\title{
Health service brokerage to improve primary care access for populations experiencing vulnerability or disadvantage: a systematic review and realist synthesis
}

Louise Thomas $^{1 *}$, Sharon Parker ${ }^{1}$, Hyun Song ${ }^{1}$, Nilakshi Gunatillaka ${ }^{2}$, Grant Russell ${ }^{2}$, Mark Harris ${ }^{1}$ and on behalf of the IMPACT Team

\begin{abstract}
Background: Individuals experiencing disadvantage or marginalisation often face difficulty accessing primary health care. Overcoming access barriers is important for improving the health of these populations. Brokers can empower and enable people to access resources; however, their role in increasing access to health services has not been well-defined or researched in the literature. This review aims to identify whether a health service broker working with health and social service providers in the community can (a) identify individuals experiencing vulnerability who may benefit from improved access to quality primary care, and (b) link these individuals with an appropriate primary care provider for enduring, appropriate primary care.

Methods: Six databases were searched for studies published between January 2008 and August 2015 that evaluated a health service broker intervention linking adults experiencing vulnerability to primary care. Relevant websites were also searched. Included studies were analysed using candidacy theory and a realist matrix was developed to identify mechanisms that may have contributed to changes in response to the interventions in different contexts.

Results: Eleven studies were included in the review. Of the eight studies judged to provide detailed description of the programs, the interventions predominately addressed two domains of candidacy (identification of candidacy and navigation), with limited applicability to the third and fourth dimensions (permeability of services and appearances at health services). Six of the eight studies were judged to have successfully linked their target group to primary care. The majority of the interventions focused on assisting patients to reach services and did not look at ways that providers or health services could alter the way they deliver care to improve access.

Conclusions: While specific mechanisms behind the interventions could not be identified, it is suggested that individual advocacy may be a key element in the success of these types of interventions. The interventions were found to address some dimensions of candidacy, with health service brokers able to help people to identify their need for care and to access, navigate and interact with services. More consideration should be given to the influence of providers on patient candidacy, rather than placing the onus on patients.
\end{abstract}

Keywords: Vulnerable populations, Health service brokerage, Primary care, Broker, Access to care, Realist evaluation, Systematic review, Candidacy theory, IMPACT study

\footnotetext{
* Correspondence: louise.thomas@unsw.edu.au

${ }^{1}$ Centre for Primary Health Care and Equity, University of New South Wales,

Sydney, NSW 2052, Australia

Full list of author information is available at the end of the article
}

(C) The Author(s). 2019 Open Access This article is distributed under the terms of the Creative Commons Attribution 4.0 International License (http://creativecommons.org/licenses/by/4.0/), which permits unrestricted use, distribution, and reproduction in any medium, provided you give appropriate credit to the original author(s) and the source, provide a link to the Creative Commons license, and indicate if changes were made. The Creative Commons Public Domain Dedication waiver (http://creativecommons.org/publicdomain/zero/1.0/) applies to the data made available in this article, unless otherwise stated. 


\section{Background}

Many population groups experiencing vulnerability or disadvantage (such as people on a low income or from culturally and linguistically diverse groups) face difficulties in accessing primary health care, in Australia [1, 2] as well as in other developed countries [3-6]. Poor access to primary care translates into disparities in health status and outcomes [7], increased rates of hospitalisation for ambulatory care-sensitive conditions [8] and increased use of emergency departments [9]. One potential strategy to address the access barriers to primary health care for population groups experiencing vulnerability is through the use of brokers.

Brokerage is a concept rooted in sociology, where it is defined as "the process of connecting actors in systems of social, economic, or political relations in order to facilitate access to valued resources" [10]. A broker, by definition, is an individual who bridges a gap in social structure. Combined with the notion of social capital (information, support, and shared norms and values that flow through established social networks), brokers have the potential to empower and enable people to access and use a range of useful resources [11]. In primary care, brokers can potentially bridge the gap between individuals and essential health resources, including access to general practitioners (GPs). Competencies for conducting this type of role have been described in the literature [12]. Brokers can provide a range of instrumental and relational functions and processes to support patients to access primary care and directly identify providers willing to treat people experiencing vulnerability who require care [13]. Therefore, brokerage has particularly useful implications for individuals from disadvantaged and marginalised communities because it can enable increased (and more equitable) access to care. Previous studies have shown that addressing gaps in the accessibility of primary health care can attenuate negative health impacts arising from sociodemographic vulnerability (advanced age, ethnicity, low socioeconomic status and low literacy) and risk factors (e.g. smoking and obesity) prevalent among groups experiencing disadvantage [14, 15]. A 2013 study found that promoting primary care utilisation among groups experiencing vulnerability can be cost-effective [16].

A study of health service brokerage to link Aboriginal and Torres Strait Islanders in Australia with appropriate mainstream primary and allied health care found that brokers were able to successfully increase access to health services in the community by supporting patients to navigate their way through the healthcare system and directly identifying service providers willing to treat them [17]. However, despite their potential, the role of brokers/health service brokers is not well defined or researched in literature, including the mechanisms that have been used to link community living patients with primary care providers. To address this gap, we conducted a realist-informed systematic review which aimed to identify whether a health service broker working with health and social service providers in the community (either through personal interactions or the use of systems and processes) can (a) identify individuals experiencing vulnerability who are likely to benefit from improved access to quality primary care, and (b) link these individuals with an appropriate primary care provider for enduring, appropriate primary care. Results are reported for studies that evaluated a health service broker intervention linking adults experiencing vulnerability to primary care.

\section{Methods}

\section{Context}

This review forms part of the IMPACT (Innovative Models Promoting Access-to-Care Transformation) study, a five year Australian and Canadian research program with the overarching aim of transforming the primary health care organisational structure to improve access to appropriate care for vulnerable populations resulting in reduced unmet need, avoidable emergency department visits and avoidable hospitalisations. Integral to the IMPACT program of work is the establishment of, and engagement with, Local Innovation Partnerships (LIPs) which comprise decision makers, researchers, field workers and local community members who support the use of knowledge exchange and partnership practices. By identifying gaps in access to appropriate and equitable community-based primary health care in their own communities, each LIP aims to develop locally relevant innovations which address these gaps.

The research question was formulated in South Eastern Melbourne, Australia, where a broad group of stakeholders (policy and decision-makers, health and human service providers and community representatives) participated in two deliberative forums aimed at identifying priority primary care access gaps in South Eastern Melbourne and interventions which have the potential to address these gaps. The group elected 'community worker' as a broad innovation to explore. Building on these forums, and further consultations with key organisations in the region, clinicians and consumer advocacy groups, the broad 'community worker' intervention was refined to the health service broker model.

Our review followed standard systematic review methodology [18]. Realist synthesis was used to appraise the evidence, with the aim of explaining why particular interventions worked or did not work. It has been used to generate evidence on many primary care interventions, including interventions to improve equitable access to health care [19]. Reporting for this review followed the RAMESES publication standards for reporting realist synthesis [20] and the Preferred Reporting 
Items for Systematic Reviews and Meta-Analyses (PRISMA) statement [21].

\section{Definitions \\ Vulnerability}

Vulnerability is relational and dynamic and arises from interactions between an individual's characteristics and their environment [22]. We have referred to groups as experiencing 'vulnerability' in this study to express that certain groups within society are exposed to contextual conditions that place them more at risk than the rest of the population [23]. This follows a Social Determinants of Health approach, which recognises that the structural determinants and conditions of daily life lead to much of the health inequity between and within countries [24].

The groups that we focused on in this study were those whose demographic, geographic, economic and/or cultural characteristics may impede or compromise their access to community-based primary care services.

\section{Brokerage}

Brokerage was defined as a role or service to bridge the gap between individuals and access to appropriate primary care for groups experiencing vulnerability.

\section{Primary care}

Primary care is usually the first contact an individual has with the health system, and can include health promotion, prevention, early intervention, treatment of acute conditions, and management of chronic conditions [25]. These services can be delivered by a range of people, including general practitioners, nurses, allied health professionals, midwives, pharmacists, dentists, and Aboriginal health practitioners [26]. Settings in which primary care is delivered includes general practice, community health centres, allied health practices, and via communication technologies [26]. In this review, we also included hospital-based primary care clinics as these clinics can be accessed on an outpatient basis.

\section{Literature search}

Comprehensive searches were conducted in Medline, Embase, All Evidence Based Medicine (EBM) reviews, CINAHL, PsychINFO and ProQuest. The search strategy was adapted for each database and included terms to encompass the types of role/worker conducting the intervention, as well as terms for the primary care setting and providers (see Additional file 1). An initial scoping review revealed that the term 'health broker' is not commonly used within the health care literature, thus a variety of different terms for the role were used in the search. The search was limited to empirical articles published in English, from OECD countries, between January 2008 and August 2015. Given the complexity around the concept of a 'health service broker', it was decided that this limited timeframe was necessary due to the extensive search which would be required to encompass all the terms used for this type of role.

Identified websites of interest from Australia, the United States of America, Canada and Europe were searched for relevant project or program evaluations. A list of possible documents for inclusion was compiled and these documents were reviewed in more depth by a second reviewer to determine relevance.

Comprehensive inclusion and exclusion criteria (Additional file 2) relating to the setting, population and intervention were developed based on the project definitions, scope of the review and knowledge gained through the deliberative forums about the key focus areas. The review was restricted to primary care settings in OECD countries (excluding primary care practices offering episodic care such as after hours or outpatient clinics) and to populations experiencing vulnerability.

Data was extracted to a template using Microsoft Access. This template was piloted using sample papers prior to data extraction commencing for the included studies. As part of the piloting process, two reviewers (LT and HS) extracted data separately for two studies. The reviewers then discussed the utility of the template, the clarity of the questions and the consistency of data extraction. The template was deemed suitable after undergoing this process. The template was designed to collect information on study type, country of origin, study location and publication details; inputs; description of the intervention, participants and setting; use of theory; dimensions of access addressed; and outcomes. Limited snowball sampling of reference lists was conducted during the data extraction phase. Relevant data from any additional publications identified for the included studies was also extracted.

\section{Quality assessment}

Studies were assessed for their rigour (credible and trustworthy methods used to generate data) and their relevance (contribution to theory building and/or testing) using the process described by O'Campo [27] (see Additional file 3). This method was chosen in recognition of the fact that the most useful information for a realist evaluation may not necessarily be contained in studies that achieve the highest scores using traditional methods of quality assessment. Using the criteria shown in Additional file 3, one point was allocated for each positive response. For rigour, studies were classified as high (7 points), moderate (4-6) points or low (0-3 points). For relevance, studies were classified as 'thick' (i.e. containing detailed program description and discussion of implementation and reasons for study findings) (3-4 points) or 'thin' (i.e. lacking detailed program 
description and discussion of implementation and reasons for study findings ( $0-2$ points). Scoring was conducted by one author (LT) and confirmed by a second author (HS). Studies were not excluded on the basis of this assessment, however, only the studies with high scores for relevance were used for the realist analysis given that these studies contained the most information on program components.

\section{Analysis}

Our analysis utilised interpretive synthesis of the literature identified. To identify an overarching theory for the realist analysis, the studies were reviewed to extrapolate whether the development or implementation of any of the interventions were informed by theory. Candidacy theory, which describes "the ways in which people's eligibility for medical attention and intervention is jointly negotiated between individuals and health services" [28] was selected as the overarching theory and the extent to which the dimensions of candidacy could be drawn out of the included studies was explored. In addition, the interventions were mapped via a realist matrix according to agency (whose actions are causing the change to occur), resources provided, and mechanisms (how the resources and the thing/person being changed interact) [29] in an attempt to get a deeper understanding of why the interventions worked, for whom and in what circumstances. Only studies that were assessed as "thick" (containing detailed program description and discussion of implementation and reasons for study findings) during the quality appraisal process (see Additional file 3) were included in this part of the analysis.

\section{Results}

A total of 1704 citations were identified from the database searches after duplicates were removed. A total of 148 citations underwent a full text review to determine their eligibility, with a further 134 records excluded at this stage. Data extraction was conducted on 13 studies, however, an additional three citations were excluded during this process on the basis that the intervention had insufficient linkage to care (one citation), referral was to specialist rather than primary care (one citation) and linkage was from specialist to primary care rather than community to primary care (one citation). One citation identified was included in the final number of citations, however, data extraction was not conducted on this paper as it was an earlier publication for a study which was already included in our citations. An additional citation which was identified during the early stages of protocol development when scoping the term 'health service broker' was added, giving a final included number of 12citations. Eleven of these citations related to separate studies, although one study [30] built on the framework of another included study [31]. No relevant evaluative studies were identified from the grey literature. Full details of the results of the screening process are detailed in the PRISMA flowchart (Fig. 1).

\section{Characteristics of studies identified}

The characteristics of the included studies are summarised in Table 1. A more detailed description of each study can be found in Table 2. Program evaluations were the predominant study type $(n=5)$. Apart from one study set in Australia, all of the studies were conducted in the United States. The primary care settings varied between community-based primary care clinic/provider $(n=3)$, hospital-based primary care clinic/provider $(n=4)$, public health clinics/agencies $(n=2)$ and community health centres $(n=4)$.

\section{Study interventions}

The interventions fell within two broad categories- those that linked participants to primary care for the purposes of screening cancer risk $(n=4)$, and those that linked to primary care for the purposes of general management $(n=7)$. Interventions targeted a wide range of groups experiencing vulnerability or multiple vulnerabilities. The most frequently targeted vulnerability was healthcarerelated disadvantage (which included being medically underserved or uninsured, having overuse of ED, having poorly controlled or unscreened disease or risk factors, or untreated chronic disease) $(n=10)$ followed by cultural and linguistic diversity $(\mathrm{n}=7)$.

\section{Study appraisal according to rigour and relevance}

The appraisal scores for rigour and relevance of each study can be found in Table 2 . No studies received the highest possible score of seven on the rigour scale, but three studies scored a six. The most common issues relating to rigour were that many of the studies did not provide details about determining sample size and did not include a comparison group. The majority of studies had a detailed program description and received the highest possible score of four on the relevance scale.

\section{Assessment of linkage to primary care}

While linkage to primary care was not necessarily the primary outcome of all the included studies, all of the studies did involve either a directly quantifiable measure of the extent to which participants were linked to primary care [32-35] or an indirect measure of linkage to care such as changes in screening behaviour or referrals to care [17, 30, 31, 36-39]. Most of these measures were assessed using follow-up surveys or questionnaires. The majority of the studies (7/11) can be said to have been successful in linking their target population with primary care (Table 3). 


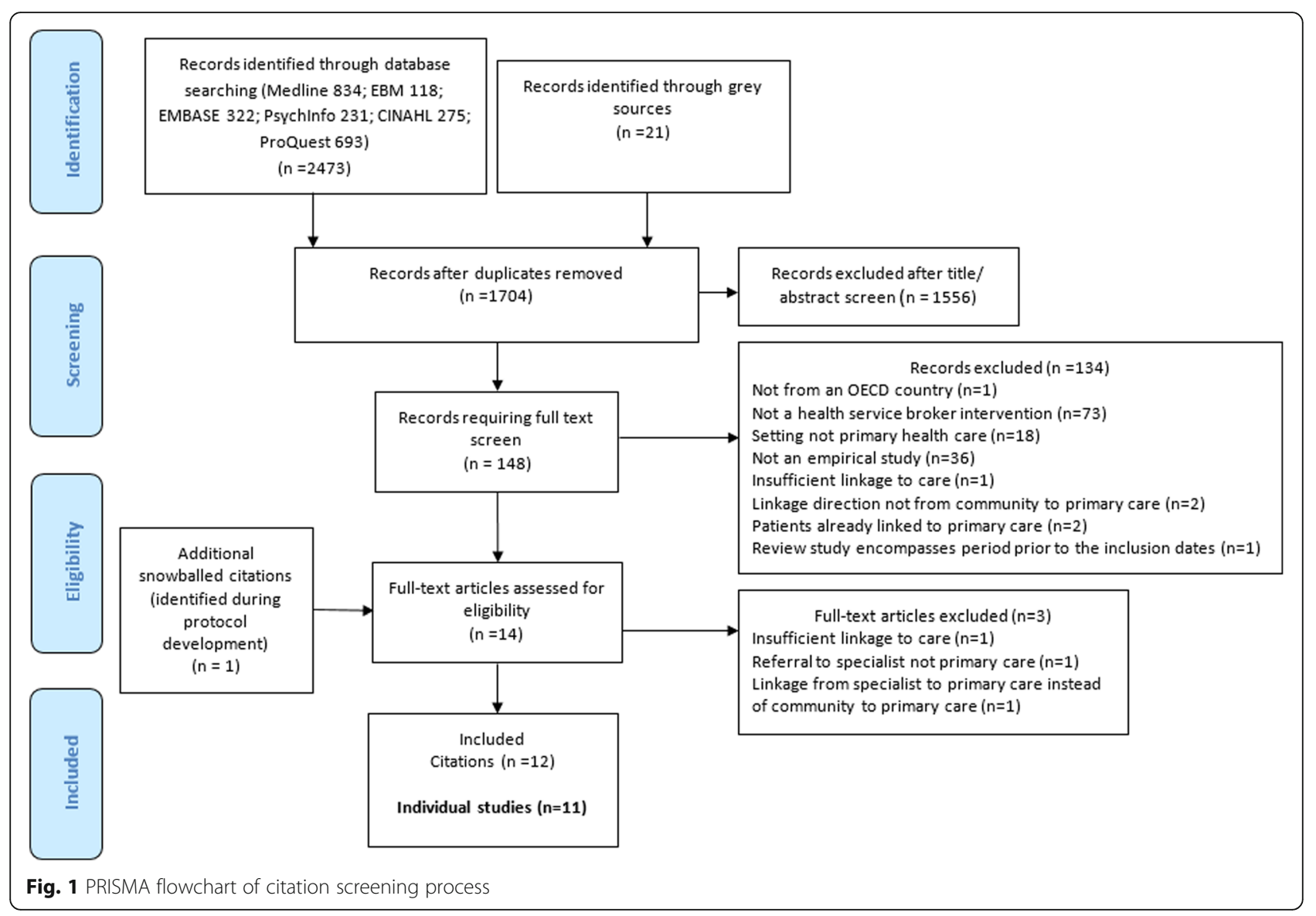

\section{Interpretive synthesis}

To identify an overarching theory, the studies were reviewed to extrapolate whether the development or implementation of any of the interventions was informed by theory. The most commonly used theory was the Transtheoretical model, which was incorporated into three interventions [30, 37, 38]. The Transtheoretical model conceptualises behaviour change as involving progress through a series of six stages of change [40]. However, this model has been criticised for its presumptions of homogeneity and the arbitrary nature of the boundaries drawn between stages [41].

One study [17] utilised candidacy theory to examine the extent to which a brokerage service could increase access to health care. Candidacy is a construct developed by Dixon-Woods et al. [28] to conceptualise access to healthcare for groups experiencing vulnerability. The seven dimensions of candidacy (identification of candidacy, navigation, permeability of services, appearances at health services, adjudications, offers and resistance, and operating conditions and the local production of candidacy) [28] capture the complexity within the notion of access to health care and also recognise that the negotiation process of a person's candidacy for care occurs within a broader environment context [42]. The candidacy construct emphasises that access is "highly dynamic and contingent, and subject to constant negotiation", with candidacy being the "core organising construct" of access [28]. This negotiation process between individuals and professionals means that candidacy is constantly being expressed and re-expressed over time and space [43], with access representing the dynamic interplay between these processes [28]. The dimensions of candidacy are recursively interrelated and produced over both time and space [43].

Candidacy builds on the foundations of the Transtheoretical model but provides descriptions for healthcare experiences rather than stages and incorporates "the influence of professionals' perceived manner, beliefs and competency on patient experience" [41]. As such, the candidacy framework can give a broader perspective of system and patient level factors influencing access to care, rather than solely focusing on patient factors. It is therefore very useful for understanding barriers and enablers to health care access [44]. Candidacy has been identified as a useful theoretical framework in a number of studies of disadvantaged populations and health care access [17, 28, 42-48]. 
Table 1 Characteristics of the studies identified

\begin{tabular}{|c|c|c|}
\hline \multicolumn{2}{|c|}{ Study characteristic } & \multirow{2}{*}{$\begin{array}{l}\begin{array}{l}\text { No of } \\
\text { studies }\end{array} \\
2\end{array}$} \\
\hline Design & Randomised controlled trial & \\
\hline & Program evaluation & 5 \\
\hline & Retrospective non-randomised cohort study & 1 \\
\hline & Pre-/post-test intervention (no control) & 1 \\
\hline & $\begin{array}{l}\text { Quasi-experimental controlled community } \\
\text { evaluation trial (pre- and post-test) }\end{array}$ & 1 \\
\hline & Mixed methods & 1 \\
\hline \multirow{4}{*}{$\begin{array}{l}\text { Primary care } \\
\text { setting }\end{array}$} & Community-based primary care clinic/provider & 3 \\
\hline & Hospital-based primary care clinic/provider & 4 \\
\hline & Public health clinics/agencies & 2 \\
\hline & $\begin{array}{l}\text { Community health centres (safety net } \\
\text { clinics/providers) }\end{array}$ & 4 \\
\hline \multirow[t]{2}{*}{ Intervention } & $\begin{array}{l}\text { Linking to primary care for screening for } \\
\text { a condition }\end{array}$ & 4 \\
\hline & $\begin{array}{l}\text { Linking to primary care for general } \\
\text { management }\end{array}$ & 7 \\
\hline \multirow[t]{8}{*}{ Vulnerability $^{a}$} & Older age & 1 \\
\hline & Socioeconomic disadvantage & 6 \\
\hline & Culturally and linguistically diverse group & 7 \\
\hline & Indigenous (Aboriginal, first nations) & 2 \\
\hline & Geographic disadvantage (rural) & 2 \\
\hline & Disability/mental health issues & 0 \\
\hline & Prison/prison leavers & 2 \\
\hline & Healthcare-related disadvantage & 10 \\
\hline
\end{tabular}

a some studies targeted multiple vulnerabilities and participants could fit into multiple groups

\section{Dimensions of candidacy applicable to the included studies}

The dimensions of candidacy from the eight studies with "thick" program description were extracted to the realist matrix (Table 4). Two dimensions of candidacy were addressed by the interventions (identification of candidacy and navigation), with some limited applicability to the third and fourth dimensions (permeability of services and appearances at health services).

\section{Identification of candidacy}

Identification of candidacy relates to the ability of people to recognise their symptoms as needing medical attention or intervention [28]. All eight interventions involved lay workers who effectively took over this role from participants as a first step. The lay workers provided outreach to identify participants that needed to be linked with a health care service (screening or ongoing management) and provided a supportive, educational and advocacy arrangement with individuals that was designed to 'lift' or 'activate' their own candidacy. These types of interventions by their nature expose the participants to resources which aim to increase their understanding about their own health and healthcare needs. Through ongoing contact or follow up the individuals contemplate their need for continued care and develop the skills and knowledge to identify and act on this in the future.

\section{Navigation}

The navigation dimension of candidacy recognises that in order to find and utilise appropriate health services, people must firstly be aware that the service exists, as well as mobilise resources to help them get to that service [28]. All eight interventions contained components that promoted the notion of navigation. Primarily, personal interactions between the broker and the participant were the key to linking the participant to primary care or screening services. These interactions were focused on raising awareness of services (through referral, or by physically transporting the person to the service). In some cases, the lay worker 'took up' candidacy on behalf of the individual through activities such as contacting providers to arrange appointments for the participant [33-37, 39]. In other situations, these resources may have facilitated the development of an individual's own candidacy, such as through increased health literacy [39]. Developing the individual's own capacity to navigate the system as opposed to the lay worker navigating the system on their behalf may have a greater impact in the longer term. However, this is difficult to assess in the studies as the interventions generally involved the provision of both types of resources- ones that may have contributed to the development of the individual's own capacity, as well as ones that involved the lay worker utilising their own capacity on behalf of the individual.

\section{Permeability of services}

Permeability of services refers to the ease with which people can use services [28]. Porous services require few qualifications of candidacy and the mobilisation of relatively few resources [28]. Permeability of services can be promoted through factors such as providing transport services, having flexible appointment structures, minimal out-of-pocket expenses and welcoming physical spaces [44]. Only one study [33] had capacity building aspects that may have contributed to increased service permeability. This study encouraged community health centres to "create, expand and enhance clinic hours where appointments are not required" [33]. However, the uptake or effect of this was not discussed.

\section{Appearances at health services}

The fourth dimension of candidacy, appearances at health services, recognises that in order to receive appropriate services, service users have to assert their needs [41]. This requires competencies such as the 


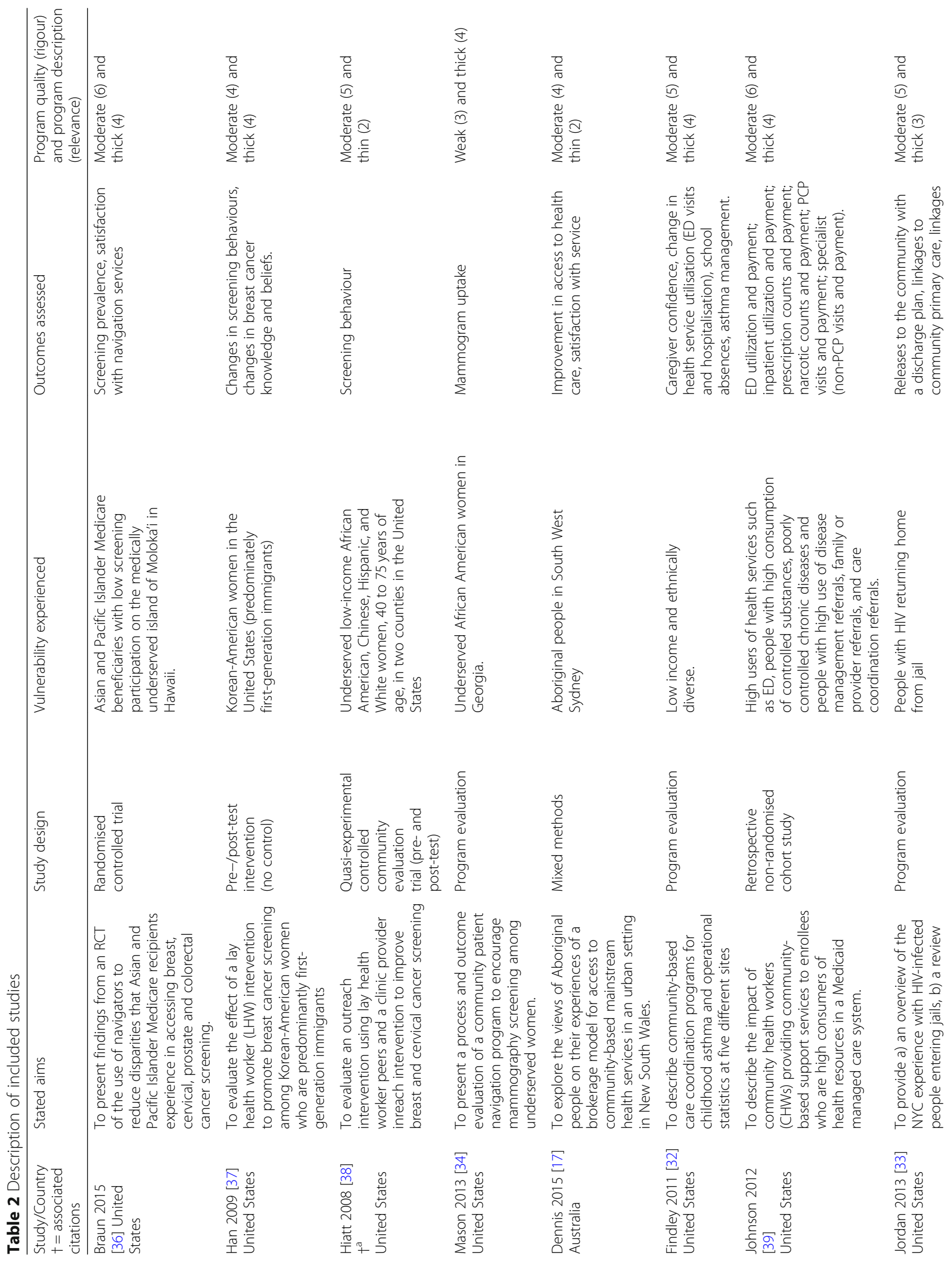




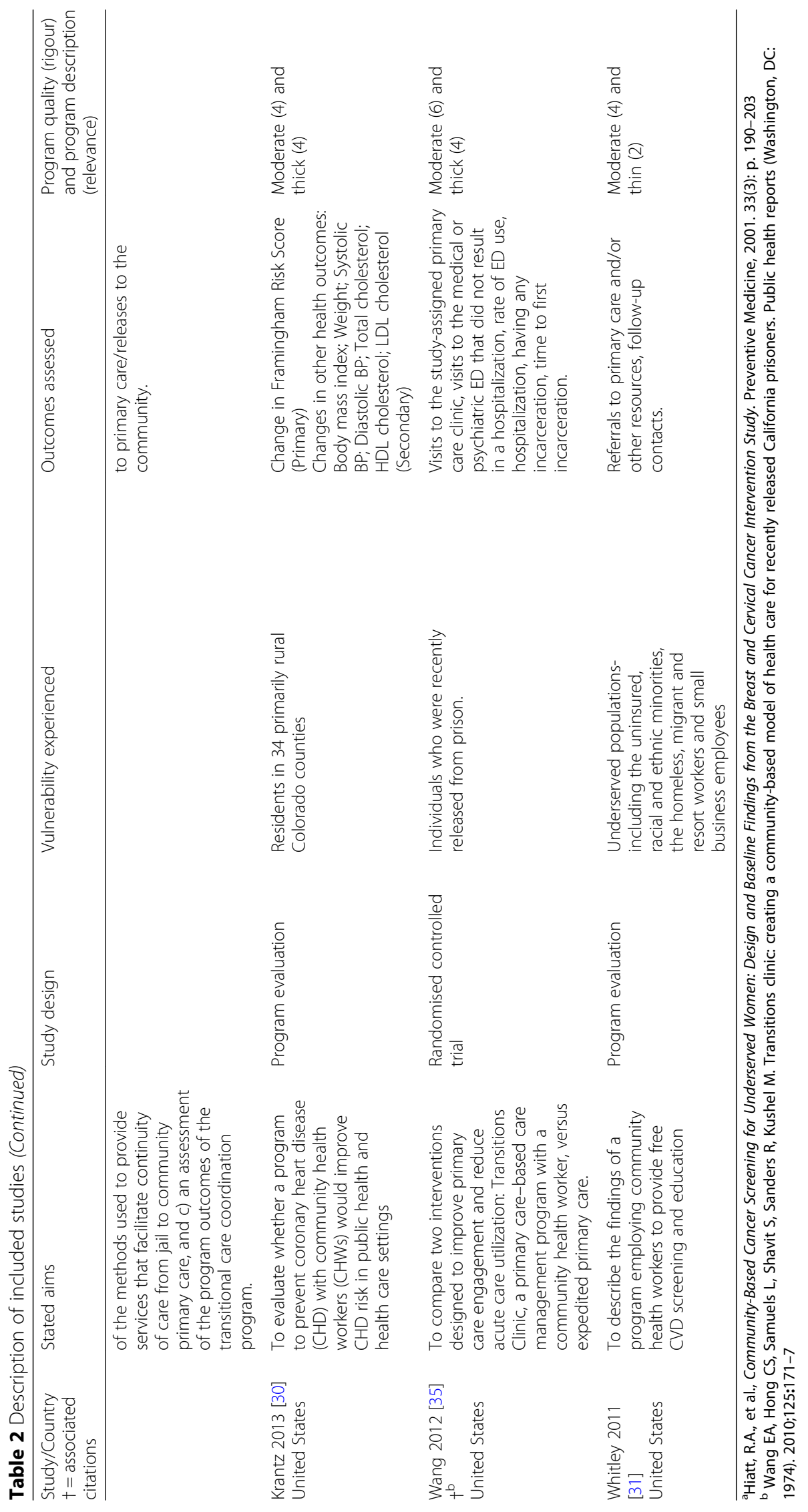




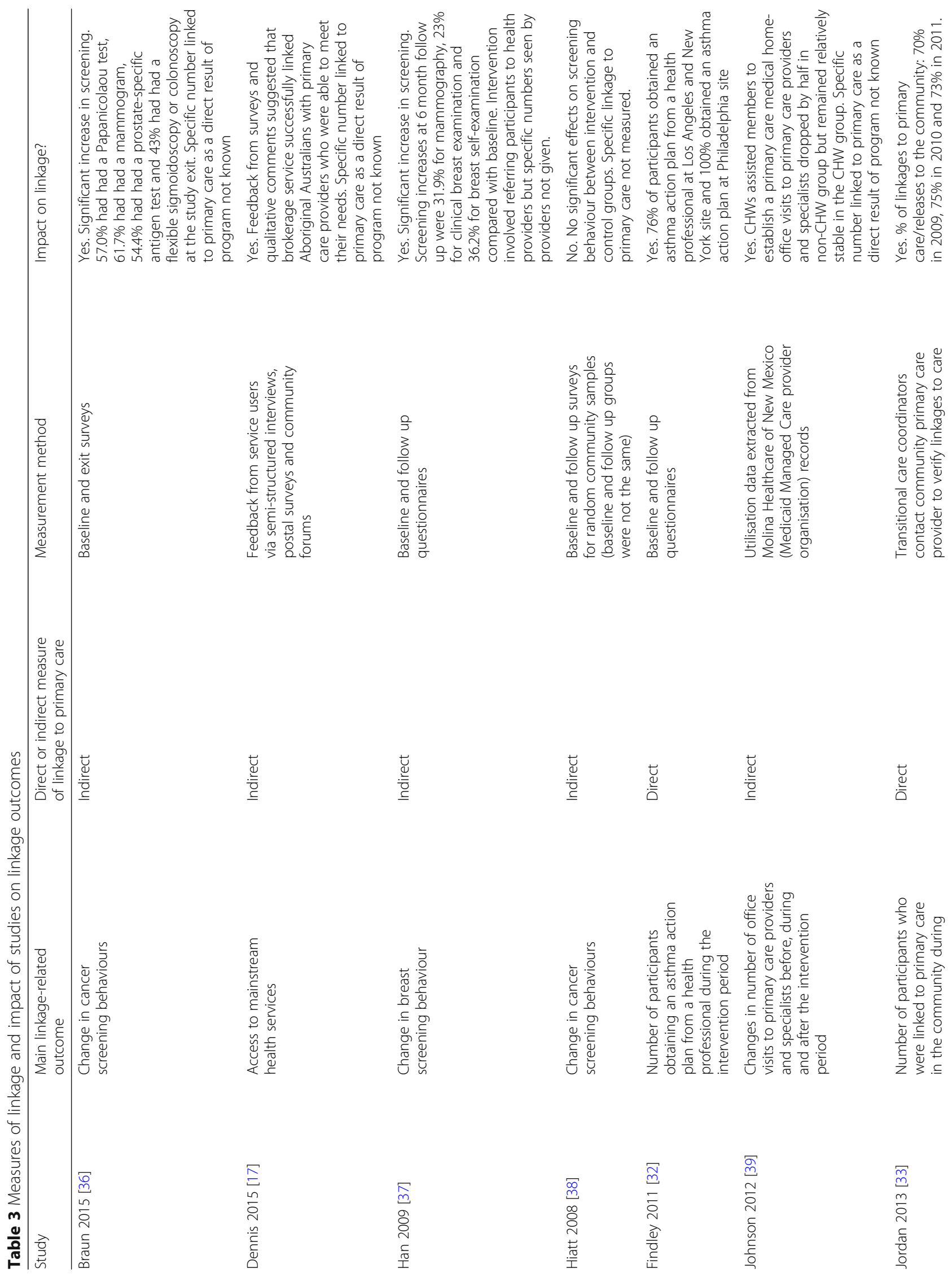




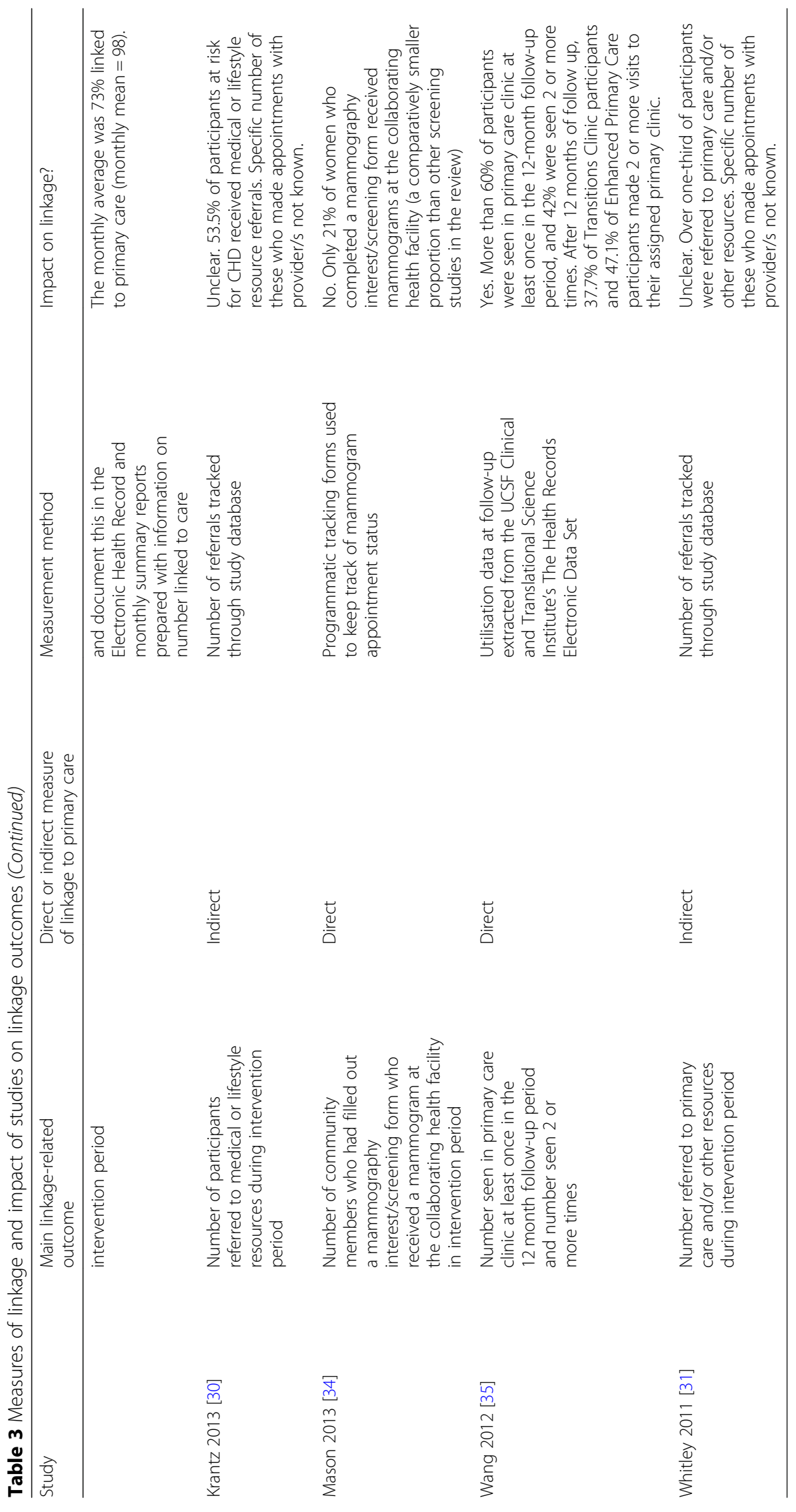




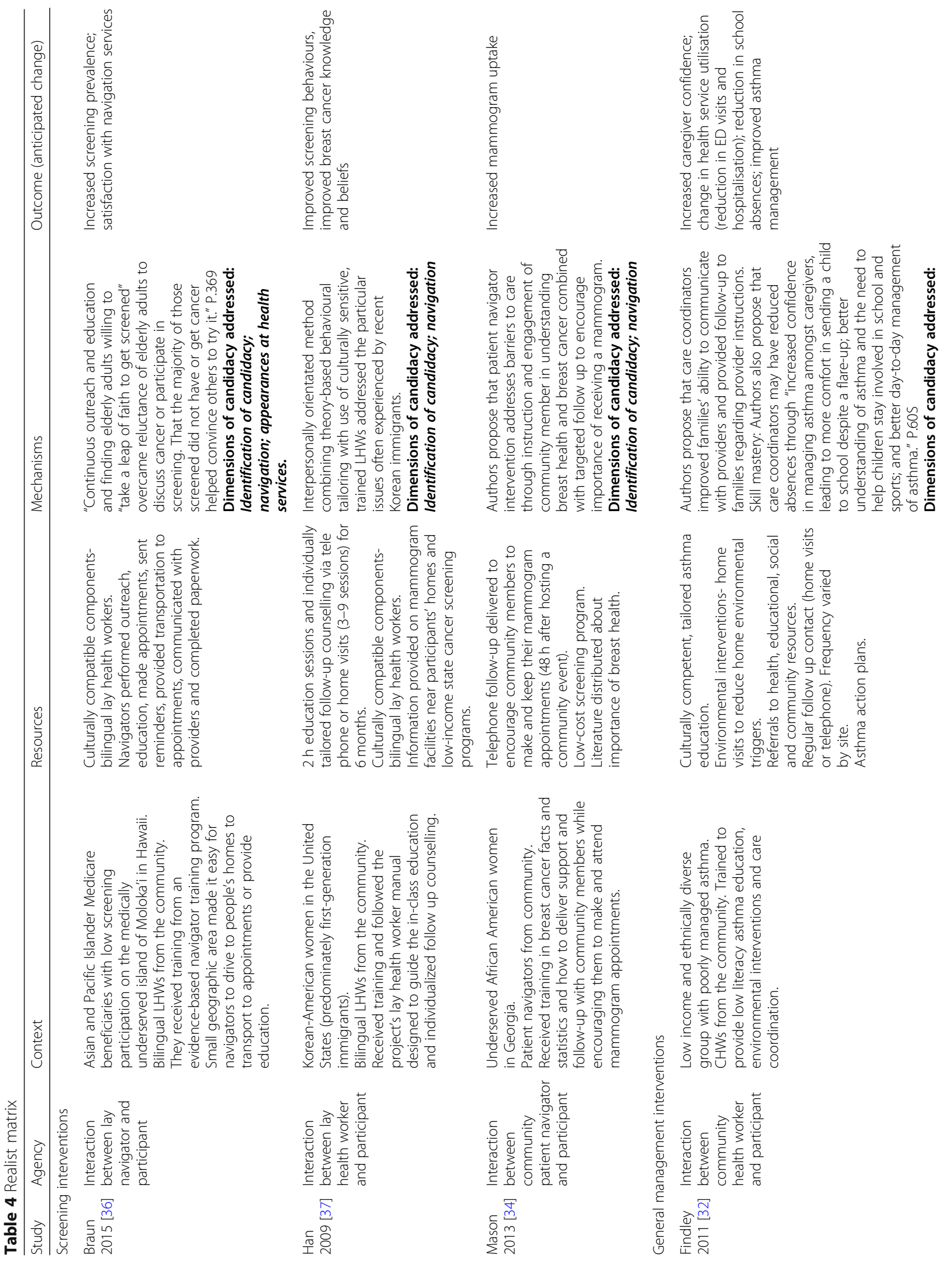




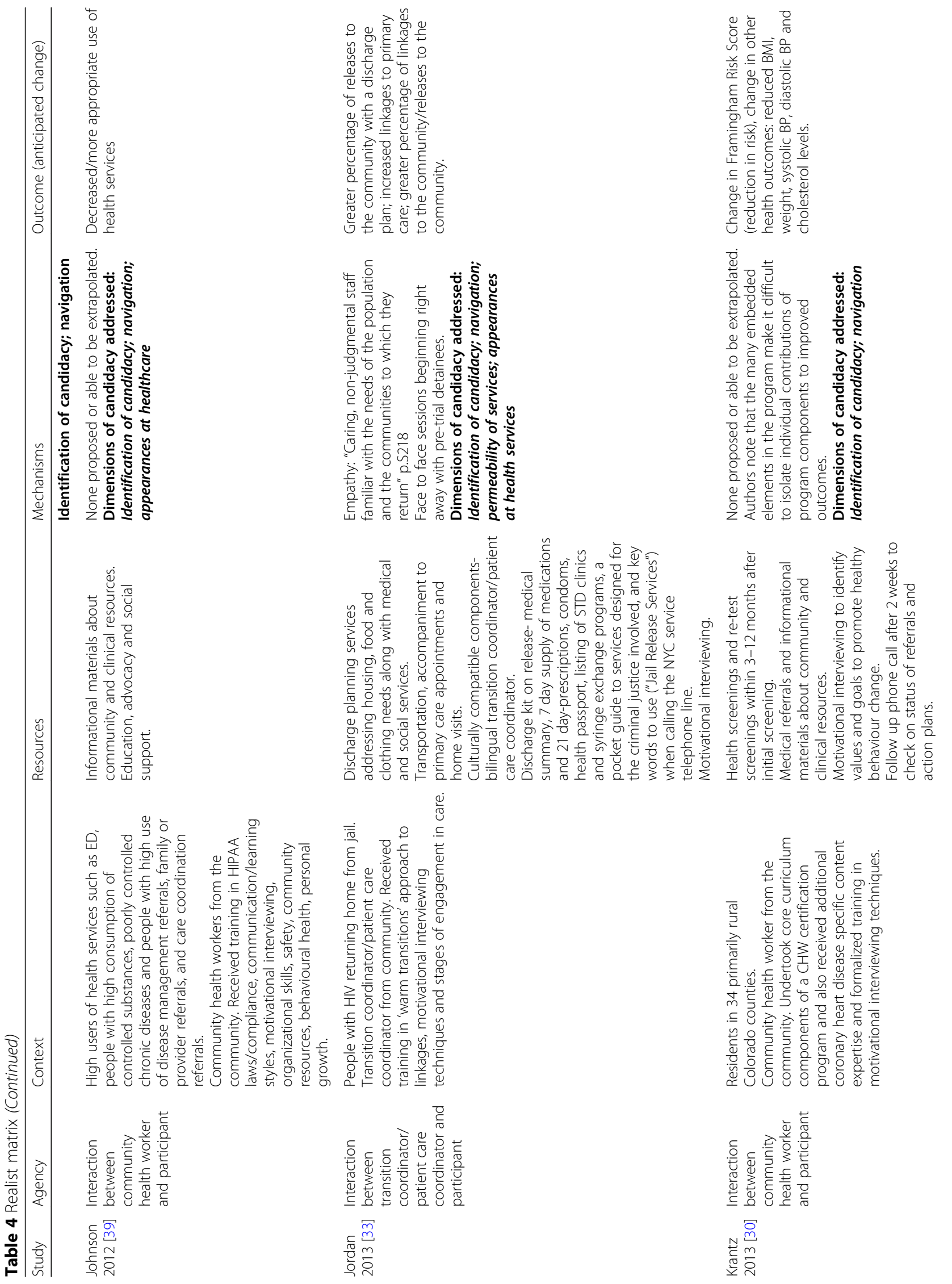




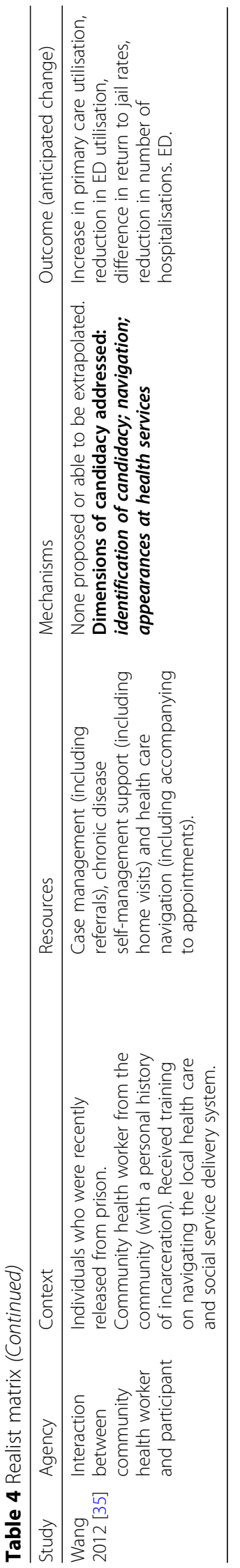


ability to understand and explain the issue [28] and could therefore be challenging for people experiencing vulnerability. Four interventions incorporated aspects relating to this dimension of candidacy. In some of the interventions, the lay worker accompanied individuals to their appointments and assisted in their interactions with the health care provider [33, 35, 36, 39]. By facilitating communication between the patient and the provider, the lay worker may have assisted the patient to assert their needs. However, assisting an individual to assert their claim may help them to progress through the system the first time, but may not have any residual effects for any future appearances at health services or serve to build the capacity of the individual. The short follow-up periods of the studies limited our ability to explore this issue within the review.

Six of the eight studies included in the realist analysis were judged to have successfully linked their target group to some form of primary care, using either directly quantifiable measures or indirect measures of linkage to care (as outlined earlier and shown in Table 4 for all included studies).

Of the studies which did not result in improved linkage to primary care $[30,31,34,38]$ (shown in Table 3), only two studies [30, 34] had significantly "thick" program descriptions to be included in the realist matrix. Both of these studies only addressed two dimensions of candidacy. However, we are unable to conclude that more than two dimensions are required to be addressed for an intervention to be successful, as both the Findley [32] and Han [37] studies also addressed only the first two dimensions of candidacy but did have a positive impact on linkage to primary care.

\section{Discussion}

Candidacy was found to be a useful way to conceptualise the influence of health service brokers on access to health care. Health service brokers were able to influence some dimensions of candidacy for individuals experiencing vulnerability, including identifying that they are a priority and eligible for health care, and the types of health care that might be appropriate. The majority of the studies were able to successfully link individuals experiencing vulnerability to primary care, which suggests that interventions which address aspects of candidacy can positively influence the journey and interactions of individuals experiencing vulnerability with health services and providers to ultimately improve access to health care. While we were not able to identify for which groups this might work better, we were able to identify that advocacy on behalf of the individual until the participant has been supported to be able to recognise and negotiate their own needs for healthcare may be a key element in the success of these types of interventions. It should be noted that while brokering primary care may increase access to health services, it is not a complete solution to health inequity. Tackling health inequity in a holistic way requires taking action on the social determinants of health [49], however, this is beyond the scope of this review.

Many of the studies identified through the review either directly stated or implied that advocacy by individuals, such as community health workers or lay health workers, was a key part of the intervention. The Community Preventive Services Task Force findings from a recent review of interventions that used community health workers to prevent cardiovascular disease in high risk populations emphasised the unique position of community health workers as trusted community members to advocate on behalf of individuals and communities and help build capacity [50]. Interventions utilising professional staff rather than community members should consider the implications of this for the advocacy component of the role. Relationships may need to be built over time to establish trust with the community. Further, attention should be given to the reporting lines and organisational embeddedness of the broker as this may enhance or constrain their ability to advocate on behalf of the patient.

The lack of attention given to the patient/provider interactions in the study is probably a reflection of the limited scope of the studies, but could be a criticism of the interventions as they appear to have been driven by an inherent assumption that once people had been assisted to access a provider, that they would then continue to seek or receive the care that they needed from this provider. In reality, this may not be the case as the identification of need by a provider does not necessarily mean that people will also recognise (or prioritise) this need and utilise the services available, or that they will receive appropriate care from this provider and/or service. Resistance (both active and passive) has implications for service provision and interventions should include measures to address resistance, such as incorporating follow-up and ongoing contact with individuals into the intervention design.

The influence of providers on patient candidacy should not be overlooked. The fact that not many of the studies discussed system level changes or capacity building activities to improve permeability of health services suggests that the majority of the interventions are focused on only one side of the problem and as such, are likely to be short term fixes only. These interventions place the onus on the individual patient to change or work harder to reach the service, when in fact the providers themselves might need to increase the permeability of services in order to allow more people to navigate through the system, without the need for interventions. The Access framework by Levesque et al. [51] also supports the need to look 
beyond patient factors alone to overcome issues of access to health care. The Access framework describes access as being two-sided, with service level factors interacting with corresponding abilities of persons, along a healthcare continuum to generate access. While Candidacy theory [28] recognises the influence of the factors beyond the individual (e.g. the setting and environment in which care takes place), it does not clearly delineate these into two 'sides'. Future interventions should aim to address both patient and service level factors in order to improve access as this review has identified that there is an overemphasis on user responsibility compared to service responsibility. For example, services should be tailored to the community to enable the influence of the local environment on candidacy to be recognised and addressed, rather than utilising a "one size fits all approach". The Australian National Safety and Quality Health Service Standards (second edition) [52] strongly emphasise the importance of partnering with consumers to plan, design, deliver, measure and evaluate systems and services. Primary care services that are not currently "permeable" to patients experiencing vulnerability should take steps to break down these barriers by engaging with the community and learning from their lived experiences.

\section{Review limitations}

The generalisability of results is limited by the small number of studies identified in the review and the varying methodological quality of the studies. Although a realist approach was utilised to try and identify the mechanisms behind the interventions, many studies, even those providing qualitative data, were largely unable to shed light on this. This issue has been reported by other authors conducting realist reviews- a review of published realist reviews identified that the authors of these publications frequently reported that they were unable to identify details on the mechanisms by which an intervention was expected to work [53]. The scope of the review had to be widened as it could not be determined whether participants in the studies were linked to an enduring form of primary care or whether contact with providers was a one-off, given that the majority of studies had short follow-up periods of less than 6 months. As a result, some of the included interventions had more of a focus on linking to primary care so that participants were adherent to screening recommendations, rather than on linking participants to a regular form of primary care to meet a wider range of health needs. More evidence is needed as to whether positive intervention effects can be sustained, as the studies included in this review generally conducted follow-up for a period of 6 months or less from the end of the intervention.

\section{Conclusions}

Specific mechanisms that may have contributed to changes in response to the interventions in the different contexts were not able to be identified, although advocacy may be a key element in the success of these types of interventions. The majority of the studies were able to link individuals experiencing vulnerability to primary care and the interventions addressed several dimensions of candidacy. In particular, the brokers helped people to identify their need for care and to access and navigate services.

\section{Additional files}

Additional file 1: Search strategy adapted for each database. (DOCX $16 \mathrm{~kb}$ )

Additional file 2: Inclusion and exclusion criteria. (DOCX $20 \mathrm{~kb}$ )

Additional file 3: Quality assessment. (DOCX $17 \mathrm{~kb}$ )

Abbreviations

GPS: General practitioners; IMPACT: Innovative Models Promoting Access-to-Care Transformation; LIPs: Local Innovation Partners

\section{Acknowledgements}

This review was conducted as part of the Innovative Models Promoting Access-to-Care Transformation (IMPACT) Program.

The IMPACT investigators are:

Prof Grant Russell, School of Primary Health Care, Monash University, Australia.

A/Prof Jeannie Haggerty, Department of Family Medicine, McGill University, Canada.

Dr. Jean-Frederic Levesque, Bureau of Health Information of New South Wales, Sydney, Australia.

Prof Mark Harris, Centre for Primary Health Care and Equity, University of New South Wales, Australia.

A/Prof Simone Dahrouge, Bruyère Research Institute, University of Ottawa, Ottawa, Canada.

A/Prof Virginia Lewis, Australian Institute for Primary Care and Ageing, La Trobe University, Melbourne, Australia.

A/Prof Cathie Scott, Community Health Sciences and Sociology, University of Calgary, Calgary, Canada.

Professor Nigel Stocks, Discipline of General Practice, University of Adelaide, Adelaide, Australia.

This review was conducted in collaboration with IMPACT's Local Innovation Partnership in Victoria, comprising health service managers, researchers, clinicians and community workers. We also acknowledge the commitment provided by the research teams and primary care communities in both Australia and Canada.

\section{Funding}

The IMPACT (Innovative Models Promoting Access-to-Care Transformation) study is a five year research program funded by the Canadian Institutes of Health Research (TTF-130729) Signature Initiative in Community-Based Primary Health Care, the Fonds de recherche du Québec - Santé, and the Australian Primary Health Care Research Institute, which is supported by a grant from the Australian Government Department of Health, under the Primary Health Care Research, Evaluation and Development Strategy. The information and opinions contained in this paper do not necessarily reflect the views or policy of these funding agencies. The funding body did not have a role in the design of the study, nor in the collection, analysis, and interpretation of data or writing the manuscript.

Availability of data and materials

Data available on request from the authors.

Authors' contributions

LT contributed to the design of the review, designed and conducted the search, adjudicated and appraised studies, extracted and analysed data and 
drafted the manuscript. SP coordinated the review, contributed to the project methodology and design of the review, designed and conducted the search, adjudicated studies, extracted and analysed data and reviewed the manuscript. HS contributed to the design of the review, designed and conducted the search, adjudicated and appraised studies, extracted and analysed data and reviewed the manuscript. NG coordinated the deliberative forums, question development and the Local Innovation Partnership in Melbourne, contributed to the design of the review, adjudicated studies, conducted the grey literature search and reviewed the manuscript. GR designed the IMPACT program of work, contributed to the project methodology and design of the review, analysed and interpreted data and reviewed the manuscript. MH designed the IMPACT program of work, contributed to the project methodology and design of the review, adjudicated studies, analysed and interpreted data and reviewed the manuscript. All authors read and approved the final manuscript.

\section{Ethics approval and consent to participate}

Not applicable.

\section{Consent for publication}

Not applicable.

\section{Competing interests}

The authors declare that they have no competing interests.

\section{Publisher's Note}

Springer Nature remains neutral with regard to jurisdictional claims in published maps and institutional affiliations.

\section{Author details}

${ }^{1}$ Centre for Primary Health Care and Equity, University of New South Wales, Sydney, NSW 2052, Australia. ${ }^{2}$ The Southern Academic Primary Care Research Unit, School of Primary Health Care, Monash University, Notting Hill, Victoria 3168, Australia.

Received: 21 August 2018 Accepted: 9 April 2019

Published online: 29 April 2019

\section{References}

1. McGrail MR, Humphreys JS. A new index of access to primary care services in rural areas. Aust N Z J Public Health. 2009;33:418-23.

2. Spike EA, Smith MM, Harris MF. Access to primary health care services by community-based asylum seekers. Med J Aust. 2011;195:188-91.

3. Harris MF. Access to preventive care by immigrant populations. BMC Med. 2012;10:55.

4. Asada Y, Kephart G. Equity in health services use and intensity of use in Canada. BMC Health Serv Res. 2007;7:41.

5. Chapman JL, Zechel A, Carter YH, Abbott S. Systematic review of recent innovations in service provision to improve access to primary care. $\mathrm{Br} J \mathrm{Gen}$ Pract. 2004;54:374.

6. Starfield B, Shi L, Macinko J. Contribution of primary care to health systems and health. Milbank Q. 2005;83:457-502

7. Politzer RM, Yoon J, Shi L, Hughes RG, Regan J, Gaston MH. Inequality in America: the contribution of health centers in reducing and eliminating disparities in access to care. Med Care Res Rev. 2001;58:234-48.

8. Starfield B. The effectiveness of primary health care. In: Lakhani M, editor. A celebration of general practice. Oxon: Radcliffe Medical Press; 2003. p. 19-36

9. Bodenheimer T, Pham HH. Primary care: current problems and proposed solutions. Health Aff (Millwood). 2010;29:799-805.

10. Stovel K, Shaw L. Brokerage. Annu Rev Sociol. 2012;38:139-58.

11. Scott C, Hofmeyer A. Networks and social capital: a relational approach to primary healthcare reform. Health Res Policy Syst. 2007;5:9.

12. Risendal B, Whitley E, Valverde P, Kellar-Guenther Y. Training patient navigators for a reformed health system. In: Calhoun EA EA, editors. Patient navigation: overcoming barriers to care. New York: Springer; 2018. p. 41-60.

13. Peart $A$, Lewis $\vee$, Brown $T$, Russell G. Patient navigators facilitating access to primary care: a scoping review. BMJ Open. 2018;8.

14. Shi L, Macinko J, Starfield B, Politzer R, Wulu J, Xu J. Primary care, social inequalities, and all-cause, heart disease, and cancer mortality in US counties, 1990. Am J Public Health. 2005;95:674-80.
15. Starfield B, Shi L. Policy relevant determinants of health: an international perspective. Health Policy. 2002;60:201-18.

16. Enard KR, Ganelin DM. Reducing preventable emergency department utilization and costs by using community health workers as patient navigators. J Healthc Manag. 2013;58:412-27 discussion 28.

17. Dennis S, Hasan I, Jackson Pulver L, Wilson I, Zwar N. Experiences and views of a brokerage model for primary care for aboriginal people. Aust Health Rev. 2015;39:26-32.

18. Centre for Reviews and Dissemination: systematic reviews. In: CRD's guidance for undertaking reviews in health care. York: CRD, University of York; 2009.

19. Hoare KJ, Mills J, Francis K. The role of government policy in supporting nurse-led care in general practice in the United Kingdom, New Zealand and Australia: an adapted realist review. J Adv Nurs. 2012;68:963-80.

20. Wong G, Greenhalgh T, Westhorp G, Buckingham J, Pawson R. RAMESES publication standards: realist syntheses. BMC Med. 2013;11:1-14.

21. Moher D, Liberati A, Tetzlaff J, Altman DG. The PG. preferred reporting items for systematic reviews and meta-analyses: the PRISMA statement. PLoS Med. 2009;6:e1000097.

22. Luna F, Vanderpoel S. Not the usual suspects: addressing layers of vulnerability. Bioethics. 2013;27:325-32.

23. Frohlich $\mathrm{KL}$, Potvin $\mathrm{L}$. Transcending the known in public health practice. Am J Public Health. 2008:98:216-21.

24. Marmot M, Friel S, Bell R, Houweling TAJ, Taylor S. Closing the gap in a generation: health equity through action on the social determinants of health. Lancet. 2008;372:1661-9.

25. Department of Health. Primary care. http://www.health.gov.au/internet/ main/publishing.nsf/Content/primarycare. Accessed 27 Febr 2018.

26. Australian Institute of Health and Welfare. Primary health care in Australia: AlHW; 2016. https://www.aihw.gov.au/reports/primary-health-care/primaryhealth-care-in-australia/contents/about-primary-health-care

27. O'Campo P, Kirst M, Tsamis C, Chambers C, Ahmad F. Implementing successful intimate partner violence screening programs in health care settings: evidence generated from a realist-informed systematic review. Soc Sci Med. 2011;72:855-66.

28. Dixon-Woods M, Cavers D, Agarwal S, Annandale E, Arthur A, Harvey J, Hsu R, Katbamna S, Olsen R, Smith L, et al. Conducting a critical interpretive synthesis of the literature on access to healthcare by vulnerable groups. BMC Med Res Methodol. 2006:6:35.

29. Better Evaluation. Realist matrix. https://www.betterevaluation.org/en/ evaluation-options/realist matrix. Accessed.

30. Krantz MJ, Coronel SM, Whitley EM, Dale R, Yost J, Estacio RO. Effectiveness of a community health worker cardiovascular risk reduction program in public health and health care settings. Am J Public Health. 2013;103:e19-27.

31. Whitley EM, Main DS, McGloin J, Hanratty R. Reaching individuals at risk for cardiovascular disease through community outreach in Colorado. Prev Med. 2011;52:84-6.

32. Findley S, Rosenthal M, Bryant-Stephens T, Damitz M, Lara M, Mansfield C, Matiz A, Nourani V, Peretz P, Persky W, et al. Community-based care coordination: practical applications for childhood asthma. Health Promot Pract. 2011;12:52S-62S

33. Jordan AO, Cohen LR, Harriman G, Teixeira PA, Cruzado-Quinones J, Venters $H$. Transitional care coordination in new York City jails: facilitating linkages to care for people with HIV returning home from Rikers Island. AIDS Behav. 2013;17(Suppl 2):S212-9.

34. Mason TA, Thompson WW, Allen D, Rogers D, Gabram-Mendola S, Arriola KR. Evaluation of the Avon Foundation community education and outreach initiative community patient navigation program. Health Promot Pract. 2013;14:105-12.

35. Wang EA, Hong CS, Shavit S, Sanders R, Kessell E, Kushel MB. Engaging individuals recently released from prison into primary care: a randomized trial. Am J Public Health. 2012;102:e22-9.

36. Braun $\mathrm{KL}$, Thomas WL, Domingo J-LB, Allison AL, Ponce A, Haunani Kamakana P, Brazzel SS, Emmett Aluli N, Tsark JU. Reducing cancer screening disparities in Medicare beneficiaries through cancer patient navigation. J Am Geriatr Soc. 2015;63:365-70.

37. Han HR, Lee H, Kim MT, Kim KB. Tailored lay health worker intervention improves breast cancer screening outcomes in non-adherent KoreanAmerican women. Health Educ Res. 2009:24:318-29.

38. Hiatt RA, Pasick RJ, Stewart S, Bloom J, Davis P, Gardiner P, Luce J. Cancer screening for underserved women: the breast and cervical Cancer intervention study. Cancer Epidemiol Biomark Prev. 2008;17:1945-9. 
39. Johnson D, Saavedra P, Sun E, Stageman A, Grovet D, Alfero C, Maynes C, Skipper B, Powell W, Kaufman A. Community health workers and medicaid managed care in New Mexico. J Community Health. 2012;37:563-71.

40. Prochaska JO, DiClemente CC, Norcross JC. In search of how people change: applications to addictive behaviors. Am Psychol. 1992;47:1 102-14.

41. Methley A, Campbell S, Cheraghi-Sohi S, Chew-Graham C. The value of the theoretical framework of candidacy in exploring access and experiences of healthcare services. Health Psychology Update. 2016;25:3-11.

42. Koehn S. Negotiating candidacy: ethnic minority seniors' access to care. Ageing Soc. 2009;29:585-608.

43. Garrett CR, Gask LL, Hays R, Cherrington A, Bundy C, Dickens C, Waheed W, Coventry PA. Accessing primary health care: a meta-ethnography of the experiences of British south Asian patients with diabetes, coronary heart disease or a mental health problem. Chronic Illness. 2012;8:135-55.

44. Peiris D, Brown A, Howard M, Rickards BA, Tonkin A, Ring I, Hayman N, Cass A. Building better systems of care for aboriginal and Torres Strait islander people: findings from the Kanyini health systems assessment. BMC Health Serv Res. 2012;12:369.

45. Dennis $\mathrm{S}$, Noon T, Liaw ST. Is there a role for a primary health nurse in a learning support team in a disadvantaged high school? Evaluation of a pilot study. Aust J Prim Health. 2016;22:530-8.

46. Bristow K, Edwards S, Funnel E, Fisher L, Gask L, Dowrick C, Chew Graham C. Help seeking and access to primary care for people from "hard-to-reach" groups with common mental health problems. International journal of family medicine. 2011;2011

47. Kovandžić M, Chew-Graham C, Reeve J, Edwards S, Peters S, Edge D, Aseem S, Gask L, Dowrick C. Access to primary mental health care for hard-to-reach groups: from 'silent suffering' to 'making it work'. Soc Sci Med. 2011;72:763-72.

48. Abbott P, Magin P, Davison J, Hu W. Medical homelessness and candidacy: women transiting between prison and community health care. Int J Equity Health. 2017;16:130.

49. Freeman T, Baum F, Lawless A, Jolley G, Labonte R, Bentley M, Boffa J. Reaching those with the greatest need: how Australian primary health care service managers, practitioners and funders understand and respond to health inequity. Australian Journal of Primary Health. 2011;17:355-61.

50. Community Preventive Services Task Force. Cardiovascular Disease Prevention: Interventions Engaging Community Health Workers- Task Force Finding and Rationale Statement. 2015. http://www.thecommunityguide. $\mathrm{org} / \mathrm{cvd} /$ RRCHW.html. Accessed 1 June 2016.

51. Levesque J-F, Harris MF, Russell G. Patient-centred access to health care: conceptualising access at the interface of health systems and populations. Int J Equity Health. 2013;12:18.

52. Care ACoSaQiH. National Safety and Quality Health Service Standards. 2nd ed. Sydney: ACSQHC; 2017.

53. Berg RC, Nanavati J. Realist review: current practice and future prospects. Journal of Research Practice. 2016;12:Article R1.

Ready to submit your research? Choose BMC and benefit from:

- fast, convenient online submission

- thorough peer review by experienced researchers in your field

- rapid publication on acceptance

- support for research data, including large and complex data types

- gold Open Access which fosters wider collaboration and increased citations

- maximum visibility for your research: over $100 \mathrm{M}$ website views per year

At BMC, research is always in progress.

Learn more biomedcentral.com/submissions 